\title{
Correction to: Estimation of the area-specific suspended sediment yield from discrete samples in different regions of Belgium
}

\author{
Jean Van Campenhout ${ }^{1}$ (D) . François Petit ${ }^{1} \cdot$ Alexandre Peeters $^{1} \cdot$ Geoffrey Houbrechts $^{1}$
}

Published online: 24 January 2022

c) Springer-Verlag GmbH Germany, part of Springer Nature 2022

\section{Correction to: J Soils Sediments}

https://doi.org/10.1007/s11368-021-03076-w

The following errors are found in the originally published article:

1. The layout of the Abstract section is not correct in which subheadings are not correctly presented. The subheadings should be in bold and separate from the first word of the sentence.

2. The supplementary material included in the originally published article is not correct. This has been resolved.

The original article has been corrected.

Supplementary Information The online version contains supplementary material available at https://doi.org/10.1007/s11368-022-03141-y.

Publisher's Note Springer Nature remains neutral with regard to jurisdictional claims in published maps and institutional affiliations.

The original article can be found online at https://doi.org/10.1007/ s11368-021-03076-w.

Jean Van Campenhout

jean.vancampenhout@uliege.be

1 Department of Geography, UR Spheres, Hydrography and Fluvial Geomorphology Research Centre, University of Liège, 4000, Sart-Tilman, Liege, Belgium 